\title{
Restaurando el pueblo de Dios en la España franquista. Las misiones de la Asesoría Eclesiástica de Sindicatos, 1949-1972
}

\author{
Restoring God's People in Francoist Spain. The Missions \\ of the Asesoría Eclesiástica de Sindicatos, 1949-1972
}

\author{
Francisco Bernal García \\ Universidad de Sevilla \\ fbernal@us.es
}

Recibido: 7-X-2014

Aceptado: 9-IV-2015

\section{Resumen}

Entre 1949 y 1972 la Asesoría Eclesiástica de Sindicatos llevó a cabo misiones periódicas en gran parte del territorio español con la finalidad de contribuir al proceso de recatolización que la jerarquía eclesiástica española había puesto en marcha tras la Guerra Civil. Estas misiones incorporaban un repertorio de actos religiosos de clara raigambre barroca cuya finalidad era lograr una identificación unánime entre la población y la Iglesia católica. No obstante, el análisis de los datos de asistencia a las misiones revela que éstas, más que generar una auténtica recatolización, sirvieron para reafirmar modelos de comportamiento religioso preexistentes.

Palabras clave: Asesoría Eclesiástica de Sindicatos, Misiones, Catolicismo, Franquismo, España, Siglo XX.

\begin{abstract}
Between 1949 and 1972 the Asesoría Eclesiástica de Sindicatos carried out regular missions in most of the Spanish territory with the aim of contributing to the process of re-catholization that the Spanish ecclesiastical hierarchy had launched after the Civil War. These missions incorporated a repertoire of religious events which showed a clear Baroque root and whose purpose was to achieve the population's full identification with the Catholic Church. Nevertheless, an analysis of the missions attendance data reveals that this strategy did not achieve an authentic re-catholization, but rather served to reaffirm previously existing models of religious behaviour.
\end{abstract}

Keywords: Asesoría Eclesiástica de Sindicatos, Missions, Catholicism, Francoism, Spain, 20th Century. 


\section{Introducción}

A lo largo de la historia de la Iglesia católica española, las misiones han ocupado un lugar destacado como instrumento de evangelización para las masas. En esencia, una misión era una campaña religiosa que se desarrollaba en una localidad durante un número determinado de días, generalmente entre siete y quince. En el transcurso de esos días un grupo de misioneros pertenecientes al clero regular, llegados desde fuera de la localidad, organizaba una serie de actos públicos de carácter religioso en los que intentaba involucrar a toda la población. Estas campañas buscaban revitalizar la vida religiosa de pueblos y ciudades y, especialmente, reforzar la labor pastoral de la Iglesia en zonas donde la presencia del clero era escasa o donde se observaba una cristianización "deficiente", debido a los bajos índices de práctica religiosa de sus habitantes.

Nacidas del Concilio de Trento, las misiones se desarrollaron entre los siglos XVI y XVIII como uno de los métodos preferidos de la jerarquía eclesiástica para hacer llegar su mensaje a la población. Numerosas investigaciones en el ámbito de la historia moderna han analizado esta técnica de comunicación religiosa, poniendo de relieve sus implicaciones culturales, sociales e, incluso, políticas. $^{1}$

Menos estudiado ha sido el hecho de que la Iglesia siguiese otorgando a las misiones un papel destacado durante los siglos XIX y XX. Las misiones no son sólo parte de la historia moderna de España, sino también de su historia contemporánea. Durante todo el siglo XIX y las tres primeras décadas del siglo XX la Iglesia las fomentó como respuesta al proceso de secularización impulsado por la aparición del liberalismo, primero, y del republicanismo y el socialismo, más tarde. De este modo, lo que había sido una técnica evangelizadora característica de la religiosidad barroca pasó a convertirse en un arma para la defensa de una cultura tradicional católica que se sentía amenazada por los nuevos paradigmas emanados de la modernidad. ${ }^{2}$

Con la implantación de la $2^{\text {a }}$ República en 1931 la actividad misional se vio considerablemente reducida. El clima de enfrentamiento entre la Iglesia y

1. Véase, a modo de ejemplo: Rico CAllado, Francisco L., Misiones populares en España entre el Barroco y la Ilustración, Valencia, Institució Alfons el Magnànim, 2006; PALOMO, Federico, "Limosnas impresas. Escritos e imágenes en las prácticas misioneras de interior en la península ibérica (siglos XVI-XVII)", Manuscrits. Revista d'història moderna, $\mathrm{n}^{\circ}$ 25 (2007), pp. 239-265.

2. Mateo AvilÉs, Elías de, "Las santas misiones en la diócesis de Málaga durante el siglo XIX”, en C. Álvarez Santaló et alii (coords.), La religiosidad popular, II, Vida y muerte: la imaginación religiosa, Barcelona, Anthropos - Fundación Machado, 1989, pp. 174-189; Ruiz SÁncheZ, José L., "Cien años de propaganda católica: las misiones parroquiales en la archidiócesis hispalense (1848-1952)", Hispania Sacra, 50:101 (1998), pp. 275-326. 
un régimen político de inequívoca vocación laicista, como era el republicano, no favorecía la celebración de una manifestación religiosa como la misión, buena parte de cuyos actos se llevaban a cabo en la vía pública y, por tanto, precisaban de una colaboración activa de las autoridades locales. Las escasas misiones que se realizaron se concentraron durante el bienio radical-cedista y se vieron rodeadas a menudo de tensiones: pueblos hubo en los que la llegada de los misioneros fue saludada con una amenaza de huelga general por parte de los sindicatos obreros. ${ }^{3}$

Sin embargo en 1939, con el final de la Guerra Civil, esta situación cambió radicalmente. La Iglesia católica vio en la victoria del Ejército franquista la oportunidad para llevar a cabo una profunda re-evangelización de la sociedad española. Con la derrota republicana quedaban expulsadas de la vida pública las fuerzas políticas que habían actuado como vanguardia del proceso de secularización. Para la jerarquía eclesiástica éstas eran las circunstancias ideales para iniciar un ambicioso proyecto de recatolización de masas destinado a restaurar la España católica tradicional, entendida como una comunidad sin fisuras, donde fe y práctica religiosas vertebrasen la vida social cotidiana. ${ }^{4}$

Dentro de este proyecto de reconquista católica, a las misiones les fue asignado un papel de enorme relevancia. Desde comienzos de la década de 1940 se pusieron en marcha campañas misionales masivas que se reprodujeron periódicamente durante las décadas de 1940 y 1950. En muchas diócesis fueron misionadas todas y cada una de las localidades que las integraban, pudiéndose decir que la posguerra constituyó una auténtica "edad de oro" de las misiones en la historia del catolicismo español. ${ }^{5}$

Las misiones de posguerra se caracterizaron por llevar a cabo una fuerte movilización de masas en los espacios públicos de pueblos y ciudades. Los actos misionales irrumpían en el espacio urbano con sus rosarios de la aurora, procesiones, vía crucis y misas de campaña. El tiempo de lo cotidiano -del trabajo, de la educación o de la vida en familia- quedaba supeditado al tiempo de lo sagrado. Para la jerarquía eclesiástica estos actos religiosos masivos constituían una constatación del triunfo de la Iglesia sobre sus enemigos. Durante el período republicano se había pretendido negar la consustancialidad entre la cultura

3. Copado, Bernabé, Crónicas misionales de Andalucía, Cádiz, Imprenta Casa Niño Jesús, 1973, p. 262.

4. Casanova, Julián, La Iglesia de Franco, Madrid, Temas de Hoy, 2001, pp. 235 y ss.

5. Callahan, William J., "The Evangelization of Franco's New Spain", Church History, ${ }^{\circ}$ 56 (1987), pp. 491-503 y La Iglesia católica en España (1875-2002), Barcelona, Crítica, 2002, pp. 360 y ss; Alfonsi, Adela, "La recatolización de los obreros en Málaga, 1937 1966. El nacionalcatolicismo de los obispos Santos Olivera y Herrera Oria", Historia Social, no 35 (1999), pp. 119-134. 
española y el catolicismo. Ahora, la movilización de masas en torno a los actos misionales evidenciaba que la Iglesia había salido victoriosa del envite y que quienes habían pretendido limitar o anular su influencia social habían sido derrotados.

Durante las décadas de 1960 y 1970 la Iglesia española se vio convulsionada por las conclusiones del Concilio Vaticano II. Muchos sacerdotes se replantearon los métodos de evangelización tradicionales y cuestionaron la idea misma de reconquista católica como modelo de religiosidad deseable para la sociedad española. ${ }^{6}$ Conviene subrayar, sin embargo, que estos cambios no se tradujeron en un abandono de las misiones. Muy al contrario, éstas siguieron realizándose durante toda la década de 1960 y durante los primeros años de la de 1970, auspiciadas por los sectores más tradicionalistas del episcopado. La idea de que las misiones fueron un elemento distintivo del primer franquismo que, indirectamente, se desprende de la lectura de algunos textos resulta, por lo tanto, errónea. ${ }^{7}$ Indudablemente, con el paso de los años las misiones fueron perdiendo espectacularidad y poder de convocatoria, pero no por ello vieron alterado lo esencial de sus contenidos.

El resurgir experimentado por las misiones en las décadas de 1940 y 1950 no constituyó un fenómeno exclusivo de España, sino que es constatable también, tras la $2^{a}$ Guerra Mundial, en otros países europeos de tradición católica, como Francia o Italia. En Francia destacó la labor desarrollada por el "Centre Pastoral des Missions à l'Intérieur" (CPMI), organismo inspirado en los planteamientos de sociólogos católicos como Fernand Boulard, mientras que en Italia el mayor esfuerzo recayó sobre los jesuitas, con misioneros destacados como Riccardo Lombardi, quien llegaría a ser conocido como "el micrófono de Dios". ${ }^{8}$

El "revival" misionero vivido en Francia e Italia durante la segunda posguerra mundial compartía unas premisas de partida parecidas al experimentado en España después de la Guerra Civil. En los tres casos los misioneros estaban alentados por un "espíritu de reconquista" que les llevaba a considerar que la secularización era un proceso que podía ser revertido mediante el activismo

6. Sobre el impacto del Concilio: Moreno SeCo, Mónica, La quiebra de la unidad: nacionalcatolicismo y Vaticano II en la diócesis de Orihuela-Alicante, 1939-1975, Alicante, Instituto de Cultura Juan Gil-Albert, 1999.

7. Orensanz, Aurelio L., Religiosidad popular española, Madrid, Editora Nacional, 1974, pp. 9-22; Urbina, Fernando, "Formas de vida de la Iglesia en España: 1939-1975", en R. Belda et alii Iglesia y sociedad en España: 1939/1975, Madrid, Editorial Popular, 1977, pp. 11-20.

8. BOUlard, Fernand, Premiers itinéraires en sociologie religieuse, Paris, Les Éditions Ouvrières, 1954; SANI, Roberto, "La Civiltà Cattolica" e la politica italiana nel secondo dopoguerra (1945-1958), Milano, Vita e Pensiero, 2004, pp. 169 y ss; Fouilloux, Étienne, Les chrétiens français entre guerre d'Algérie et mai 1968, Paris, Parole et Silence, 2008, pp. 243-257. 
religioso. Sin embargo, las misiones francesas presentaron una importante diferencia con respecto a las españolas: abandonaron el modelo barroco, caracterizado por los actos espectaculares realizados en plena vía pública, sustituyéndolo por una nueva técnica de misionar que se pretendía fuese más "discreta" y "humilde". Las grandes manifestaciones de masas fueron sustituidas por actos parroquiales, charlas para grupos reducidos y visitas a los domicilios de personas que se pensaba podían ser receptivas al mensaje misional. Se pretendía huir de la imagen de triunfalismo eclesiástico que tradicionalmente había rodeado a las misiones y que, en el pasado, había generado hostilidad hacia las mismas por parte de grupos laicistas. ${ }^{9}$ Esta ruptura con el modelo tradicional de misión es menos observable en el caso italiano, donde los actos masivos y el afán por sacralizar el espacio público fueron las notas dominantes, lo cual provocó que desde el Partido Comunista Italiano se acusara los misioneros de actuar en connivencia con las estrategias electorales de la Democracia Cristiana. ${ }^{10}$

Tanto en Francia como en Italia, desde finales de la década de 1950, el movimiento misional entró en una profunda crisis que le llevaría prácticamente a diluirse durante la década siguiente. La renovación pastoral impulsada por el Concilio Vaticano II desvalorizó la idea de una "reconquista católica", impulsando en su lugar un nuevo modelo de evangelización basado en el "diálogo con el otro" y en el "compromiso social como forma de testimonio". En este nuevo contexto, fueron muchos los sacerdotes y laicos que desarrollaron una concepción negativa de la misión, a la que terminaron considerando como una manifestación antitética de las nuevas formas conciliares. En España este cuestionamiento de las misiones es observable también en algunos sacerdotes durante la década de 1960 pero, a diferencia de lo ocurrido en Francia o Italia, el mismo no fue lo suficientemente fuerte como para diluir el fenómeno misional, el cual se mantuvo vigente durante toda la década de 1960 e, incluso, dio sus últimos coletazos a comienzos de la de 1970.

\section{La Asesoría Eclesiástica de Sindicatos}

De entre las instituciones vinculadas a la Iglesia católica española que se especializaron en la organización de misiones hubo una que destacó de una mane-

9. Prudhomme, Claude, "Le grand retour de la mission?", Vingtième Siècle. Revue d'Histoire, $n^{\circ} 66$ (2000), pp. 119-132; SORREL, Christian, "Les diòceses français à l'heure Boulard. Missions générales et pastorale d'emsemble en Savoie dans les années 1950 et 1960", en A. Becker et alii (dirs.), Écrire l'histoire du christianisme contemporain. Autour de l'œuvre d'Étienne Fouilloux, Paris, Éditions Karthala, 2013, pp. 287-299.

10. MACCONI HECKNER, Ilaria, "La politicizzacione della vita religiosa in Italia nel secondo dopoguerra", Schweizerische Zeitschrift für Religions-und Kulturgeschichte, no 106 (2012), pp. 375-391. 
ra particular por su perseverancia y por su fidelidad al modelo tradicional de misión: la Asesoría Eclesiástica de Sindicatos. Esta institución fue creada en 1944 como un organismo integrado por sacerdotes adjunto a la organización sindical oficial del régimen franquista. Inspirada en el triple lema de "instruir en lo religioso, vigilar en lo moral e impulsar en lo social", su finalidad principal era utilizar los recursos que el sindicalismo franquista le ofrecía para desarrollar campañas de apostolado entre los trabajadores. La Asesoría se financiaba con fondos procedentes de la cuota sindical, pagada por los trabajadores y empresarios que se encontraban integrados en los sindicatos, dándose así la situación de que los trabajadores se veían obligados, indirectamente, a financiar su propia evangelización. ${ }^{11}$

De entre las actividades llevadas a cabo por la Asesoría Eclesiástica de Sindicatos la más relevante fue la organización de misiones. La Asesoría inició su actividad misionera en 1949, con una campaña centrada en el norte de la provincia de León, y la mantuvo ininterrumpidamente hasta comienzos de la década de 1970. En mayo de 1972 se llevó a cabo la última actividad misional organizada por la Asesoría de la que he encontrado referencias: una campaña de misiones por diferentes pueblos de la provincia de Jaén. ${ }^{12}$

En teoría, las misiones de la Asesoría Eclesiástica de Sindicatos presentaban un importante elemento distintivo con respecto a las organizadas directamente por las diócesis o por otros institutos religiosos: eran misiones que se llevaban a cabo en zonas donde existían grandes concentraciones de población obrera. Los misioneros de la Asesoría se presentaban a sí mismos como especialistas en la evangelización de obreros. Su misión consistía en acometer la reconquista católica de la sociedad española por el flanco en que ésta era más susceptible de encontrar resistencias: el de una clase obrera a la que se consideraba sumida en un proceso de "apostasía". ${ }^{13}$

Sin embargo, un análisis detallado de lo que ocurría durante las misiones organizadas por la Asesoría nos lleva a concluir que éstas estaban muy lejos de constituir una iniciativa destinada sólo a los obreros. Las misiones se lle-

11. Sobre la creación de la Asesoría Eclesiástica de Sindicatos: Bernal García, Francisco, El sindicalismo vertical. Burocracia, control laboral y representación de intereses en la España franquista (1936-1951), Madrid, CEPC - Asociación de Historia Contemporánea, 2010, pp. 191-195. También: LóPez GALlego, Ma Silvia, "La difícil relación de la Iglesia y la Organización Sindical Española durante el primer franquismo: la creación de la Asesoría Eclesiástica de Sindicatos (1944-1959)", Hispania Sacra, 56:114 (2004), pp. 661-686.

12. Archivo General de la Administración (AGA), Asesoría Eclesiástica de Sindicatos (AES), Misiones en la provincia de Jaén, 1972, Caja 24-2.

13. Asesoría EClesiástica Nacional de Sindicatos, Segunda Reunión de Asesores Eclesiásticos. Memoria, Madrid, Imprenta Sindical, 1946, pp. 20 y ss. 
vaban a cabo, efectivamente, en localidades donde los obreros tenían un importante peso demográfico e incluían actos religiosos especialmente dirigidos a ellos, pero incluían también actos dirigidos a miembros de otros grupos sociales: empresarios, comerciantes, funcionarios... Las misiones de la Asesoría buscaban constituir una experiencia total que involucrase al conjunto de la población de una determinada comunidad, sin excepciones por razón de edad, sexo o clase social.

No podemos afirmar, por lo tanto, que existiesen diferencias significativas entre las misiones organizadas por la Asesoría y las que eran organizadas directamente por las diócesis o por otras instituciones religiosas. El repertorio de actos organizados, los objetivos perseguidos y el público al que se pretendía llegar eran muy similares. En todos los casos se seguía el modelo de misión espectacular, con gran movilización de masas en las calles y orientado a moralizar la vida pública y lograr el máximo número de confesiones y comuniones. ${ }^{14}$ Sin embargo, en el ámbito de las órdenes religiosas se constata desde finales de la década de 1950 la existencia de voces críticas con este modelo de misión tradicional, al que se juzgaba ineficaz y mal adaptado a la dinámica de la sociedad moderna, y favorables a la adopción del "nuevo modelo de misión" que había desarrollado en Francia la CPMI. Estas críticas encontraron eco en el seno de la Federación del Apostolado de la Palabra (FEDAP), organismo creado en 1956 que reunía a representantes de diferentes órdenes religiosas con la finalidad de poner en común experiencias en los ámbitos de las misiones, la catequesis y los ejercicios espirituales, si bien dentro de la propia Federación fueron también numerosas las opiniones favorables a la perseverancia en la misión tradicional. ${ }^{15}$ El estado actual de nuestros conocimientos no

14. Las crónicas de las abundantes misiones diocesanas llevadas a cabo en las décadas de 1940 y 1950 y, en menor medida, en la de 1960, así lo constatan. En 1943 la revista Ecclesia aseguraba que habían sido muy escasas las familias de San Sebastián y León que no hubiesen participado en las misiones diocesanas celebradas en dichas localidades; véase: Ecclesia, no 91, 1943. En 1949, en el transcurso de una misión organizada por el Obispado de Almería se llevó a cabo un "auto de fe", consistente en la quema pública de libros "de lo más corrompido": Copado, Bernabé, Crónicas misionales..., pp. 319-329. En fecha tan tardía como 1965 la Santa Misión de Sevilla, de carácter diocesano, consiguió una importante movilización de masas, utilizando como reclamo procesiones extraordinarias de algunas de las principales imágenes religiosas de la Semana Santa de dicha ciudad: Hermandad Misionera de SAn Vicente de Paúl, Sevilla: misión 1965, Madrid, La Milagrosa, 1965.

15. El debate entre misión tradicional y "nueva misión" puede ser seguido a través de: Segundo Congreso de Misiones Parroquiales, Madrid 30 de junio a 5 de julio de 1958, Madrid, El Perpetuo Socorro, 1961. De interés también: OlabuÉnAGA, Mítxel, "Misiones populares de la Congregación de la Misión en España (1704-1975). Parte 11”, en 
nos permite evaluar hasta qué punto estas opiniones renovadoras tuvieron una plasmación práctica en la forma de desarrollar las misiones, pero sí resulta evidente que la Asesoría Eclesiástica de Sindicatos se mantuvo ajena a las mismas, alineándose en todo momento con la corriente más tradicionalista. ${ }^{16}$

La geografía de las misiones de la Asesoría Eclesiástica de Sindicatos obedecía a unas pautas constantes. La Asesoría centraba sus esfuerzos en localidades de tamaño mediano o pequeño donde existían importantes concentraciones de población trabajadora asalariada. Por el contrario, nunca organizaba misiones en las capitales de provincia, si bien a menudo colaboraba con las que, organizadas por las autoridades diocesanas, se llevaban a cabo en ellas. Así, por ejemplo, la Asesoría realizó diferentes actos para obreros dentro de las misiones que, auspiciadas por el arzobispado, se llevaron a cabo en Barcelona en 1951 y en 1961, las cuales fueron consideradas en su momento como hitos espectaculares de la evangelización de masas. ${ }^{17}$

Podemos clasificar las misiones llevadas a cabo por la Asesoría Eclesiástica de Sindicatos en seis tipos diferentes, dependiendo del ámbito geográfico en que se desarrollaban: cuencas mineras, pantanos, nudos ferroviarios, litorales pesqueros, núcleos industriales y comarcas agrarias. Cada uno de estos tipos de misiones planteaba una problemática específica. ${ }^{18}$

Hasta mediados de la década de 1960 las cuencas mineras recibieron una atención prioritaria por parte de la Asesoría, la cual organizó misiones prácticamente en todas las provincias de España donde existían minas de cierta entidad: Asturias, León, Palencia, Teruel, Zaragoza, Ciudad Real, Córdoba, Huelva, Murcia, Almería y Jaén. Algunas cuencas mineras fueron visitadas de una manera particularmente reiterada por los misioneros. Así, entre 1949 y 1959, la zona minera de León llegó a ser objeto de hasta ocho campañas misionales. ${ }^{19}$

<http://somos.vicencianos.org/blog/misiones-populares-de-la-c-m-en-espana-17041975-parte-11/> [consultado: 26-VI-2014]

16. En 1951 una delegación de la Asesoría acudió a un Congreso Internacional de Apostolado Seglar, celebrado en Roma. Allí tuvieron ocasión de conocer las innovadoras experiencias desarrolladas en Francia, pero se mostraron poco impresionados por las mismas: Tenemos que aprender de la labor extranjera, pero también podemos levantar la voz dando a conocer formas de apostolado tradicionales que dan resultado halagüeño; esos "modos" modernos que en otras naciones ponen en práctica, creemos no necesitarlos hoy por hoy aquí, aun cuando reconozcamos la necesidad de intensificar el apostolado en el mundo del trabajo: AGA, AES, Congreso de Apostolado Seglar, 1952, Caja 23.

17. AGA, AES, Santa Misión de Barcelona, 1951 y 1961, Cajas 11 y 21.

18. Las misiones de la Asesoría pueden ser reconstruidas, aunque con lagunas y omisiones, a través de una publicación periódica denominada Boletín de Información de la Asesoría Eclesiástica de Sindicatos, publicada entre 1950 y 1972.

19. Boletín de Información..., no 52, 1962. 
Las misiones de pantanos se centraban en zonas donde se estaba llevando a cabo la construcción de un pantano, lo cual determinaba que existiese una fuerte concentración temporal de trabajadores inmigrantes, empleados en las obras en curso. La Asesoría consideraba a este tipo de trabajador especialmente "necesitado" de asistencia evangelizadora debido a su "desarraigo". Así, sólo entre 1949 y 1950 se llevaron a cabo misiones en embalses en construcción tales como el de Barrios de Luna (León), Gabriel y Galán (Cáceres), Entrepeñas (Guadalajara) y Yesa (Navarra). ${ }^{20}$

Una finalidad muy similar perseguían las misiones desarrolladas en nudos ferroviarios. Se llevaban a cabo en torno a estaciones de ferrocarril que concentraban a grandes contingentes de empleados de RENFE. Fue el caso de las misiones de Plasencia - Empalme y Puertollano (en 1950), Medina del Campo, Miranda de Ebro y Mérida (en 1952) o la de Monforte de Lemos (en 1953). ${ }^{21}$

Entre las misiones realizadas en litorales pesqueros las que más destacaron por su espectacularidad fueron las realizadas en la costa gallega a comienzos de la década de 1960. Entre 1960 y 1962 la Asesoría misionó todos los pueblos pesqueros situados entre El Ferrol y Ribadeo, mientras que en 1963 procedió a misionar los situados entre El Ferrol y la desembocadura del río Miño, completando de este modo su campaña evangelizadora dirigida al mundo pesquero gallego. ${ }^{22}$

Al no actuar en grandes centros urbanos, la Asesoría Eclesiástica de Sindicatos nunca pudo llevar sus misiones a los principales centros industriales del país. Pero sí llegó a organizarlas en localidades de tamaño mediano y pequeño donde existían instalaciones industriales de relevancia. Así, por ejemplo, en la provincia de Navarra, en diferentes momentos de la década de 1950, fueron misionadas localidades industriales tales como Aoiz, Mancilla u Olazagutía. En la de Gerona, también durante la década de 1950, los misioneros visitaron Blanes, Cassà de la Selva y Llagostera. Y la provincia de Santander, entra las décadas de 1950 y 1960, fue escenario de misiones que afectaron a localidades con importante actividad industrial, tales como Suances o Camargo. ${ }^{23}$

Hubo también misiones que tuvieron como denominador común el centrarse en comarcas donde la población laboral se empleaba mayoritariamente en actividades agrarias. Estas misiones fueron las que terminaron dominando entre finales de la década de 1960 e inicios de la de 1970 cuando, en el contexto de cambios socioculturales que estaba experimentando España, la Asesoría

20. Boletín de Información..., no 1, 4 y 52, 1950 y 1962.

21. Boletín de Información..., no 4, 5, 15 y 17, 1950, 1951, 1953 y 1954.

22. Boletín de Información..., n ${ }^{\circ}$ 52, 1962.

23. Boletín de Información..., no 9, 18, 43 y 52, 1952, 1954, 1960 y 1962. 
tendió a centrar sus actividades en áreas deprimidas, fuertemente afectadas por la emigración, donde tales cambios se estaban experimentando con menor intensidad y, por lo tanto, su mensaje tradicionalista era aún susceptible de encontrar seguidores. Provincias como Ávila, Zamora, Jaén o Almería concentraron la mayor actividad misionera en estos años finales. ${ }^{24}$

Algunas misiones concretas no se ajustaron a ninguno de los seis modelos descritos. Así, en la década de 1960 la Asesoría realizó conatos para extender su actividad a localidades turísticas, a las cuales consideraba "necesitadas de misión", debido al "pernicioso" impacto que la llegada de turistas estaba teniendo sobre la moralidad y las costumbres. Con esta intención se llevó a cabo, por ejemplo, la misión de Capdepera (Baleares) en 1964. No obstante, esta línea de actuación no fructificó. ${ }^{25}$

\section{El programa misional. La preparación del terreno: la "antemisión"}

Las misiones de la Asesoría se basaban en un programa de actividades perfectamente organizado en el que ningún detalle quedaba al azar. Este programa venía a reproducir, con muy pocas variaciones, el modelo de misión postridentina que se había consolidado a lo largo del siglo XVII, lo cual estaba en plena consonancia con el proceso de revitalización de los modelos barrocos de comunicación religiosa que se vivió en España después de la Guerra Civil. ${ }^{26}$

No obstante, en el caso de las misiones de la Asesoría resulta necesario subrayar que este proceso fue cronológicamente más allá del denominado primer franquismo, manteniéndose durante toda la década de 1960 e, incluso, durante los primeros años de la de 1970. La Asesoría permaneció fiel al modelo de misión barroca durante todo el segundo franquismo, ajena a los cambios culturales que estaba experimentando el país. De este modo, se alineó con los sectores eclesiásticos españoles que vivieron el período franquista como un continuo y que no experimentaron cambios significativos tras el Concilio Vaticano II. ${ }^{27}$

24. Boletín de Información..., no 72, 75 y 82, 1967, 1968 y 1972.

25. AGA, AES, Santa Misión de Capdepera, 1964, Caja 23-3.

26. Di FEBO, Giuliana, Ritos de guerra y de victoria en la España franquista, Bilbao, Desclée de Brouwer, 2002, pp. 27-38 y 69-85.

27. Sobre los procesos de continuidad y cambio en la Iglesia católica durante el segundo franquismo: CAllahan, William J., "La Iglesia católica, ¿continuidad o cambio?", en N. Townson (ed.), España en cambio. El segundo franquismo, 1959-1975, Madrid, Siglo XXI, 2009, pp. 157-165; Montero García, Feliciano, "La Iglesia dividida. Tensiones intraeclesiales en el segundo franquismo. (La crisis postconciliar en el contexto del tardofranquismo)", en M. Ortiz Heras et alii (coords.), De la cruzada al desenganche: la Iglesia española entre el franquismo y la transición, Madrid, Sílex, 2011, pp. 51-75. 
¿Pero en qué consistían exactamente las misiones de la Asesoría Eclesiástica de Sindicatos? ¿Cuáles eran las actividades que los misioneros ponían en liza con la esperanza de despertar el fervor religioso en las localidades que les acogían? Las siguientes páginas está dedicadas a analizar las principales actividades que se desarrollaban dentro de cada misión, si bien es necesario precisar que no todas las misiones englobaban todos y cada uno de estos actos, siendo numerosos los motivos por los que se podía prescindir de algunos de ellos. No obstante, estas variaciones se hacían a partir de un "corpus" central de actos que permanecía invariado y, en tal sentido, sí podemos hablar de un modelo único de misión.

La misión comenzaba con lo que en el argot de la Asesoría se denominaba la "antemisión", es decir, el trabajo de organización previo. Dicha labor implicaba, en primer lugar, obtener el permiso del obispo encargado de la diócesis donde la misión se iba a llevar a cabo. No siempre los prelados otorgaban dicho permiso. Los más refractarios a la labor de la Asesoría fueron Marcelino Olaechea Loizaga (arzobispo de Valencia entre 1946 y 1966), Antonio Pildain y Zapiain (obispo de Las Palmas entre 1936 y 1966) y Pedro Segura y Sáenz (cardenal arzobispo de Sevilla entre 1937 y 1954). Todos ellos excluyeron a la Asesoría de las actividades misionales desarrolladas en sus diócesis. La explicación proporcionada fue siempre la misma: preferían desarrollar sus propios programas misionales sin interferencias de un instituto religioso ajeno a la diócesis. ${ }^{28}$ Las misiones que estos prelados desarrollaron presentaban grandes similitudes en cuanto a organización y técnicas empleadas con las que desarrollaba la Asesoría, por lo que no cabe inferir que existiese en ellos alguna objeción al modo de misionar de ésta. ${ }^{29}$ Sí es significativo el que tanto Pildain como Segura profesasen una indisimulada antipatía hacia los sindicatos oficiales del régimen, a los cuales la Asesoría estaba vinculada y de los cuales obtenía financiación, ya que los acusaban de haber impedido el desarrollo de los sindicatos católicos y de intentar usurpar ellos mismos tal denominación. ${ }^{30}$

28. Las negativas de los prelados en: AGA, AES, Correspondencia, 1949-1950, Caja 25.

29. En el caso de Las Palmas podemos constatarlo a través del relato de las misiones organizadas por Pildain en 1944, 1948 y 1954 que encontramos en: CHIL EstéveZ, Agustín, Pildain. Un obispo para una época, $2^{\mathrm{a}}$ ed., Las Palmas, Caja Insular de Ahorros de Canarias, 1988, pp. 335-343.

30. Hemos de tener en cuenta que los sindicatos franquistas utilizaban a la Asesoría como su principal baza para ser reconocidos como "católicos". Por su parte, la Asesoría tampoco poseía un buen concepto de Pildain, a quien acusaba de haber erosionado el prestigio de los sindicatos franquistas, regalando argumentos a los críticos del régimen: AGA, AES, Sección Difusora AES nº 2, 1960, Caja 10. 
Una vez obtenidas las "licencias ministeriales", el siguiente paso consistía en seleccionar a los misioneros que iban a predicar durante la campaña. Éstos eran reclutados entre los miembros de las órdenes religiosas que mostraban mayor vocación misionera. La Asesoría tenía predilección por los capuchinos debido a que ésta era la orden a la que pertenecía el responsable de su Sección de Apostolado, Teodomiro de Villalobos. No obstante, en momentos concretos también recurría a otras órdenes, tales como dominicos, claretianos o jesuitas. Cada orden poseía su propio método de misionar. Así, por ejemplo, los capuchinos otorgaban gran importancia al vía crucis, mientras que los jesuitas intentaban trasladar a los actos misionales la estructura de los ejercicios espirituales ignacianos. En ocasiones podían surgir malentendidos o, incluso, polémicas entre misioneros debido a estas diferencias de matiz que, sin embargo, no alteraban el modelo global de misión, muy parecido en todas las órdenes religiosas. ${ }^{31}$

Tras el reclutamiento de los misioneros, la Asesoría debía contactar con los curas párrocos de las localidades que iban a ser misionadas para que fuesen preparando el terreno. Una adecuada campaña publicitaria era clave para el posterior éxito de la misión. Los párrocos debían publicitarla intensamente, informando a los feligreses de su celebración y distribuyendo los carteles y octavillas que les eran enviados desde la Asesoría. En localidades de cierta entidad lograban que el periódico y la emisora de radio locales cediesen espacios publicitarios gratuitos y en localidades pequeñas podían llegar a visitar los domicilios de cada uno de los vecinos, para invitarles personalmente a que acudiesen a los actos religiosos que habían de celebrarse. ${ }^{32}$

Al mismo tiempo, los párrocos debían informar a la Asesoría sobre la situación religiosa de sus parroquias, con la finalidad de que los misioneros conociesen el terreno que iban a pisar. Debían indicar si se trataba de un pueblo muy religioso o si, por el contrario, estaba dominado por la indiferencia. Particularmente importante era que hiciesen constar si había adultos que no estuviesen bautizados, que no hubiesen realizado la primera comunión o que conviviesen con su pareja sin estar casados, ya que durante los días de la misión estas personas iban a ser sometidas a una presión constante para que aceptasen recibir los sacramentos que les faltaban. A finales de la década de 1950, la Asesoría decidió sistematizar el proceso de recolección de información, elaborando un modelo de cuestionario único. En este cuestionario los párrocos

31. Los diferentes métodos misionales de las órdenes religiosas y, al mismo tiempo, el gran parecido existente entre todos ellos quedan de relieve en: Primer Congreso de Misiones Populares. Loyola, 1956, Sevilla, Imprenta Bergali, 1957.

32. AGA, AES, Misiones en las provincias de León y Murcia, 1951 y 1961, Cajas 23-3 y 26. 
debían hacer constar el número de habitantes de la localidad que comulgaban habitualmente cada domingo y el número de los que lo hacían una vez al año, por Pascua. Al mismo tiempo, debían indicar una serie de datos sociológicos, tales como el número de analfabetos, el número de parados o el número de periódicos que eran leídos habitualmente. También debían realizar un breve comentario sobre la situación política del pueblo, haciendo hincapié sobre cuestiones tales como si existía "caciquismo", si pervivían odios ligados a la Guerra Civil o si los pobres guardaban "resentimiento" hacia los ricos.

\section{La bienvenida a los misioneros. La misión infantil}

Una vez finalizada la labor preparatoria, podía comenzar la acción misional propiamente dicha. El día fijado para el inicio de la campaña, los misioneros hacían su "entrada solemne" en la localidad. Los misioneros se dirigían hacia la plaza central, donde les esperaba una multitud encabezada por el alcalde y otras autoridades. El alcalde daba la bienvenida en nombre del pueblo a los misioneros y éstos, a su vez, saludaban a los congregados y les informaban sobre el programa de actos a desarrollar durante los días siguientes. En localidades de cierta entidad la entrada finalizaba con una procesión de los misioneros hasta el principal templo que en ellas hubiese.

La entrada de los misioneros era un acto que ponía de relieve la estrecha relación existente entre misión y poder político local. En primer lugar, por el lugar destacado que ocupaban los representantes de dicho poder en la ceremonia. El alcalde recibía a los misioneros "en nombre de todo el pueblo", pero al mismo tiempo se destacaba, ante toda la población, junto a ellos. Al compartir el espacio de una tribuna o de un balcón junto a los misioneros, el alcalde aparecía, ante los ojos de sus conciudadanos, como receptor privilegiado del poder sobrenatural del que aquéllos eran portadores. Y junto al alcalde comparecían también, en idéntica posición de privilegio, otras autoridades de carácter político, judicial, policial o militar, dependiendo de la entidad administrativa de la localidad misionada. ${ }^{33}$

Pero el acto de la entrada de los misioneros ponía también de relieve la colaboración entre misión y poder político debido a que se trataba de un acto que había sido organizado por las propias autoridades locales. El programa misional contemplaba que los misioneros fuesen recibidos en la plaza pública por una multitud. La imagen establecida de la misión exitosa exigía que los

33. Sobre la interrelación entre Iglesia católica y poder local durante el primer franquismo: Moreno Fonseret, Roque; Moreno SeCo, Mónica, "Poder local e Iglesia durante el primer franquismo", Spagna Contemporanea, vol. 11, n 22 (2002), pp. 135-156. 
misioneros fuesen aclamados por una multitud entusiasta desde el principio. Evidentemente, esta movilización no se lograba siempre de manera espontánea. En muchos casos era necesario que el alcalde convocase previamente a los habitantes de la localidad mediante la publicación de un bando y la realización de otras acciones informales destinadas a transmitirles la idea de que el poder político esperaba de ellos que asistiesen masivamente a la entrada. ${ }^{34}$

Se producía, de este modo, una auténtica simbiosis entre misión y poder político. La misión necesitaba al poder político para poder llevar a la práctica una serie de actos religiosos que implicaban alterar el normal desarrollo de la vida cotidiana y el poder político se beneficiaba, a su vez, de la acción de los misioneros en la medida que éstos, a través de acciones no explícitas, pero sí efectivas, venían a transmitirle una especie de legitimación adicional de carácter religioso. La alianza entre Iglesia y poder político, consustancial a la naturaleza del régimen franquista, quedaba de este modo explicitada a través de la misión.

Entre la multitud que aguardaba la entrada de los misioneros no faltaba nunca la presencia de los niños y niñas en edad escolar, acompañados por sus maestros y maestras. Y precisamente a los escolares iban dirigidos los actos que se desarrollaban durante los primeros días de la campaña misional: era lo que los misioneros denominaban la "misión infantil". Ésta consistía en una serie de actos específicamente dirigidos a la infancia. Durante varios días los escolares recibían una serie de charlas catequéticas a través de las cuales los misioneros les ilustraban sobre los principios fundamentales de la fe católica. Estas charlas, celebradas en la iglesia o en la escuela, eran acompañadas de otros actos desarrollados en la vía pública como, por ejemplo, la "procesión de las banderitas", en la que cada niño portaba una pequeña bandera -bien con la enseña nacional o bien con los colores del Vaticano- mientras todos entonaban cánticos religiosos. En ocasiones, los niños podían representar en la vía pública breves piezas teatrales o, incluso, participar en una cabalgata formada por carrozas encima de las cuales representaban cuadros de temática religiosa. La misión infantil finalizaba con una misa en la cual comulgaban todos los niños que hubiesen realizado la primera comunión. ${ }^{35}$

En la "misión infantil" era fundamental la colaboración de los maestros y maestras. Éstos velaban por que todos los niños escolarizados acudiesen a los actos misionales y apoyaban activamente la labor de los misioneros, bien fuera enseñando a sus alumnos cánticos religiosos u organizando los ensayos de las piezas teatrales a representar. Puede que en ningún otro momento como en las

34. Boletín de Información..., no 41, 1960.

35. Boletín de Información..., nº 5, 1951. 
misiones quedase de relieve el sometimiento de la escuela a las estrategias evangelizadoras del clero, elemento clave de la legislación franquista en materia de enseñanza. Así las cosas, los escolares que acudían a los actos de la misión infantil constituían un auténtico "público cautivo" que carecía de la capacidad de decidir no asistir a los mismos. Los actos misionales se realizaban en horario lectivo y el maestro les hacía acudir, acompañándoles hasta los lugares en que se desarrollaban. ${ }^{36}$

Mediante la misión infantil se buscaba que los niños viesen aumentados sus conocimientos religiosos y que se sintiesen incentivados a mantener las prácticas asociadas a la fe católica. Pero los misioneros perseguían también una finalidad instrumental: captar el interés de los adultos hacia la misión. La presencia bulliciosa de niños en las calles, cantando y agitando "banderitas", creaba una ambiente de simpatía hacia la misión que predisponía a los adultos a asistir a los actos específicamente preparados para ellos. Ésta era la razón de que la "misión infantil" se desenvolviese siempre durante los primeros días de la campaña misional. ${ }^{37}$

En ocasiones, se convertía a los niños en propagandistas activos de la misión, haciéndoles recorrer el pueblo mientras lanzaban a voz en grito llamamientos tales como “¡Padres, a la misión! ¡Madres, a la misión!”. En otros casos, los misioneros pedían a los niños que, al llegar a casa, planteasen a sus padres la conveniencia de asistir a los actos misionales. Durante la misión celebrada en El Ferrol en 1960 los niños fueron instruidos para que rezasen cada noche tres avemarías "con los brazos en cruz" para lograr que sus padres asistiesen a la misión. Según el autor de la crónica misional, la estrategia dio resultado y se tradujo en una mayor presencia de adultos en los actos religiosos. ${ }^{38}$

\section{El rosario de la aurora. Las conferencias para adultos}

Finalizada la misión infantil, los misioneros podían centrarse en los actos misionales dirigidos a los adultos. Para éstos, la misión comenzaba por la mañana muy temprano, con la celebración, durante todos los días que durase la campaña, del "rosario de la aurora". Antes de la salida del sol, los fieles se concentraban en la iglesia, desde donde partían en procesión, recorriendo las calles del

36. Algunas referencias sobre la relación entre Iglesia, magisterio y escuela durante el franquismo: Peralta Ortiz, $\mathrm{M}^{\mathrm{a}}$ Dolores, La escuela primaria y el magisterio en los comienzos del Franquismo, Madrid, Universidad Pontificia de Comillas, 2012, pp. 63-65.

37. La utilización de este recurso era recomendada en los manuales para misioneros: SÁNCHEZ CÉSPEDES, Gregorio, Directorio manual teórico-práctico de misiones y ejercicios, t. I, El misionero en el púlpito. Sermones y pláticas, $3^{a}$ ed., Santander, Sal Terrae, 1961, p. 312.

38. AGA, AES, Misión en El Ferrol, 1960, Caja 23-2. 
pueblo mientras rezaban el rosario en voz alta. Finalizado el recorrido, la procesión regresaba a la misma iglesia, donde se celebraba una misa.

Tras el rosario de la aurora, a lo largo del día, se iban desarrollando diferentes actos para adultos, bien en la propia iglesia o en locales acondicionados al efecto, como teatros o cines. Estos actos consistían en conferencias doctrinales y morales dirigidas a grupos específicos configurados en función del sexo, la edad y el estado civil, siendo lo más habitual que se celebrasen conferencias especiales para mujeres casadas, mujeres solteras, hombres casados y hombres solteros.

En el transcurso de estas conferencias, los misioneros abordaban temas especialmente pensados para cada uno de estos grupos. Así, las conferencias para mujeres casadas hacían hincapié en su papel como madre y pilar sostenedor de la familia cristiana. La visión de la mujer que se transmitía en estas conferencias era fuertemente tradicionalista. La mujer debía desarrollar su experiencia vital en su ámbito natural, el hogar, y huir de la exposición pública. La principal función de la mujer casada era proporcionar una educación cristiana a sus hijos. La importancia de este papel era tal que se podía considerar a la madre corresponsable de la salvación o condenación del alma de sus hijos. Los misioneros solían incluir en sus conferencias numerosas historias moralizantes, de naturaleza deliberadamente fantástica, destinadas a impactar sobre la conciencia del auditorio. Una de las que más repetían era la del juicio de Dios a una "mala madre" que, con su falta de preocupación a la hora de educar cristianamente a sus hijos, había causado la "condenación eterna" de todos ellos. En 1959, el cronista de una misión celebrada en Candanedo de Fenar (León) aseguraba que esta historia había conmovido y consternado al auditorio. ${ }^{39}$

Por su parte, las conferencias para mujeres solteras hacían hincapié, ante todo, en el tema de la vocación. Toda mujer joven debía plantearse cuál era su vocación en la vida: el matrimonio, el celibato o la vida religiosa. En este sentido, se llevaban a cabo acciones que pretendían reforzar el compromiso de las mujeres jóvenes con la Iglesia y con la búsqueda de su verdadera vocación. Así, era habitual que el misionero pidiese a las jóvenes participantes que escribiesen en un papel un "propósito", siendo este papel quemado el último día del ciclo, como símbolo del compromiso que cada una adquiría en el cumplimiento del mismo. Del mismo modo, los misioneros intentaban institucionalizar el compromiso religioso de las jóvenes animándolas a formar una asociación piadosa, del tipo de las "Hijas de María", que habría de prolongar su existencia más allá de la duración de la misión y que centraría su actividad en la realización

39. AGA, AES, Misiones en la provincia de León, 1959, Caja 23-3. 
periódica de cultos y obras de caridad. Inevitablemente, las conferencias para mujeres solteras también contaban con una dimensión moralizante, con el misionero previniendo a su auditorio contra los peligros de la "impureza" o de los noviazgos desarrollados al margen del control familiar.

Los hombres tenían también sus conferencias específicas. A los casados se les hacía hincapié en su papel como cabezas de familia y en su responsabilidad a la hora de orientar la vida familiar en un sentido cristiano. A los de edad más avanzada se les exhortaba abiertamente a plantearse el tema de la muerte y de la necesidad de estar "en paz con Dios" en el momento en que ésta llegase. Por su parte, a los jóvenes se les prevenía contra los vicios considerados más habituales entre la juventud rural: el juego, el abuso del alcohol, la blasfemia, trabajar en domingo o el "desenfreno" durante las romerías. ${ }^{40}$

Las conferencias para mujeres, casadas o solteras, solían contar con una asistencia masiva sin necesidad de que los misioneros realizasen un particular esfuerzo propagandístico. El éxito de la misión entre la población femenina era algo con lo que se contaba desde un principio, siendo muy excepcionales los casos en que los que los actos misionales para mujeres se saldaban con un fracaso de asistencia. Muy distinta era la actitud de la población masculina. La asistencia masiva de los hombres no estaba garantizada en absoluto y los casos de baja asistencia o, incluso, de suspensión de conferencias por escasa asistencia no eran infrecuentes. Por ello, los misioneros dedicaban buena parte de sus esfuerzos a atraer a los hombres a la misión. Llenar los actos misionales con mujeres y niños no tenía especial mérito, pero lograr una nutrida presencia de hombres sí era considerado como un claro indicio de que la misión estaba transformando la actitud de la población hacia la Iglesia.

El que las mujeres presentasen una mayor predisposición que los hombres a acudir a los actos misionales era consecuencia de su mayor compromiso con la Iglesia. La asistencia de las mujeres a misa era superior a la de los hombres, hecho éste que fue constatado por la sociología religiosa entre las décadas de 1950 y 1970 en todas las regiones españolas. ${ }^{41} \mathrm{La}$ idea de que las misiones eran "cosa de mujeres y niños" parecía ser moneda corriente en numerosos pueblos.

40. En 1958, en vísperas de unas misiones en la cuenca minera de Palencia, los párrocos de localidades como Guardo o Cervera de Pisuerga, entre otras, advertían a los misioneros de que la juventud masculina de aquella zona se caracterizaba por su gusto por la blasfemia, la cantina y las diversiones, exhortándolos a que abordasen estas cuestiones durante sus charlas misionales: AGA, AES, Misiones generales de la cuenca minera palentina, 1958, Caja 24-3. Sobre los esfuerzos de la Iglesia católica en pos de la moralización de la vida pública: BERZAL DE LA ROSA, Enrique, Valladolid bajo palio. Iglesia y control social en el siglo XX, Valladolid, Ámbito, 2002, pp. 142 y ss.

41. VÁzQUEZ, Jesús $\mathrm{M}^{a}$, Realidades socio-religiosas de España, Madrid, Editora Nacional, 1967 , pp. 87 y ss. 
En muchos de ellos existía, además, todo un folklore, manifestado a través de chanzas o coplas, destinado a burlarse de los hombres que frecuentaban en "exceso" la sacristía o que, después de toda una vida apartados de las cuestiones eclesiásticas, manifestaban un súbito interés por las mismas cuando, alcanzada una edad avanzada, pensaban que la muerte podía estar cercana. Los misioneros se mostraban convencidos de que este clima creaba un auténtico miedo "al qué dirán" que retraía a los hombres de participar en los actos misionales.

Para romper este muro de indiferencia, los misioneros realizaban una apuesta decidida por involucrar a los hombres: junto con las conferencias mencionadas, los hombres protagonizaban, en exclusiva, uno de los actos públicos centrales de la misión, el "vía crucis". El vía crucis es una procesión penitencial que busca rememorar el camino recorrido por Jesús cuando se dirigía hacia la crucifixión. En las misiones, solía llevarse a cabo de noche y sólo podían participar los hombres, reservándose a las mujeres el papel de espectadoras. Otorgando a los hombres el protagonismo absoluto en uno de los actos clave de la misión, los misioneros esperaban superar su prevención hacia la misma. Al mismo tiempo, estaban convencidos de que el ambiente de sobrio recogimiento en que se desenvolvía la procesión podía llevar a los hombres participantes a replantearse su relación con Dios y elegir un estilo de vida "más cristiano".

\section{La misión en minas y fábricas: los actos para obreros}

Las conferencias arriba analizadas eran actos abiertos a mujeres y hombres de cualquier clase social. Pero paralelamente a las mismas se desarrollaban también conferencias y charlas especialmente dirigidas a obreros. No olvidemos que la Asesoría Eclesiástica de Sindicatos justificaba su razón de ser en la recristianización de la clase obrera. Los misioneros de la Asesoría consideraban esencial el que su mensaje llegase a los obreros y que sirviese para transformar la cultura de éstos, en el sentido de hacerla más favorable a la religión católica y las instituciones eclesiásticas.

Por lo general, los actos misionales para obreros se realizaban en el propio centro de trabajo y dentro de la jornada laboral. Para ello era imprescindible llegar a un acuerdo previo con los directores de las empresas. Éstos debían ceder sus instalaciones y autorizar a los empleados a dedicar una hora de su jornada laboral a escuchar el mensaje de los misioneros. Lo ideal era que la empresa "regalase" esta hora, no obligando a los empleados a recuperarla, ni descontándola del salario. En una abrumadora mayoría de casos los directores de las empresas mostraban una magnífica predisposición a colaborar. Así, durante una misión celebrada en la localidad leonesa de Sabero, en 1959, la empresa mine- 
ra Hulleras de Sabero y Anexas S.A. costeó algunos de los gastos de la misión y el día en que se celebró el vía crucis de los hombres decidió otorgar un "indulto laboral", perdonando a todos los trabajadores que en aquel momento sufrían algún tipo de sanción disciplinaria. ${ }^{42}$ Por el contrario, los casos de directivos de empresas que se negaban a prestar ningún tipo de colaboración a la misión eran muy escasos y, por ello mismo, resultaban llamativos para los misioneros.

El hecho de que los actos misionales para obreros se desarrollasen en las propias instalaciones de trabajo y con la colaboración activa de la dirección de la empresa ha llevado a cuestionar la voluntariedad de la asistencia a los mismos. Así, William J. Callahan no cree que en el contexto político de la década de 1940 los trabajadores tuviesen opciones de negarse a acudir a los actos misionales organizados en las fábricas. ${ }^{43}$ Desde este punto de vista, los obreros, al igual que los escolares, vendrían a constituir un "público cautivo" de los misioneros.

Los misioneros abordaban el tema de la voluntariedad de la asistencia a los actos para obreros con calculada ambigüedad. Con frecuencia, insistían en que la asistencia era voluntaria. No obstante, el hecho de que tales actos contasen casi siempre con la asistencia de toda la plantilla laboral, sin excepciones, hace dudar de la veracidad de tales declaraciones, más aún si tenemos en cuenta que, como reconocían los propios misioneros, los obreros solían estar mal predispuestos hacia las misiones. ${ }^{44}$ Hubo casos de obreros que se negaron a acudir a los actos misionales celebrados en el lugar de trabajo, pero estas actitudes eran muy infrecuentes y su propia excepcionalidad explica que los misioneros las subrayasen, con sorpresa, en sus crónicas. Así, durante la ya mencionada misión de El Ferrol de 1960, un grupo de trabajadores de carga y descarga del puerto se negó a acudir a un acto de treinta minutos a pesar de que la empresa consignataria PYSBE había anunciado que les remuneraría dicho tiempo: afirmaron que preferían seguir trabajando antes que escuchar a los misioneros. ${ }^{45}$

Hay un hecho significativo: la asistencia de los obreros a los actos misionales que se desarrollaban fuera del recinto de las empresas parece haber sido, en líneas generales, muy reducida, de lo que se deduce que si no hubieran

42. AGA, AES, Misiones en la provincia de León, 1959, Caja 23-3.

43. Callahan, William J., La Iglesia católica..., pp. 360 y ss.

44. En algunos casos concretos, los misioneros reconocieron que habían existido coerciones. Así, durante una misión celebrada en 1971, un misionero reconoció que los empleados de la Central Hidroeléctrica Puente Bibey, en la frontera entre las provincias de Orense y Zamora, habían sido obligados por la dirección de la misma a acudir a un acto misional celebrado en sus instalaciones: AGA, AES, Misiones en la zona de Sanabria, 1971, Caja 23-3.

45. AGA, AES, Misión en El Ferrol, 1960, Caja 23-2. 
sido abordados en su lugar de trabajo, se habrían mantenido, mayoritariamente, al margen de la misión. Lo ocurrido en dos misiones celebradas en la zona minera de La Unión (Murcia) en 1949 y 1961 así lo demuestra. Durante la misión de 1949 no se programaron actos en los centros de trabajo. La consecuencia fue que la misión se saldó con un sonado fracaso, como reconocieron los propios misioneros. Los obreros no acudieron a los actos misionales y éstos apenas se sostuvieron con los niños de las escuelas y algunas mujeres. ${ }^{46}$ En 1961 La Unión y los municipios cercanos volvieron a ser misionados, pero en esta ocasión los misioneros se mantuvieron en constante colaboración con los directores de las empresas, quienes concedieron horas libres para que los obreros escuchasen las charlas dentro de los propios centros de trabajo. Algunas empresas incluso concedieron una gratificación extraordinaria con motivo de la misión. A diferencia de lo ocurrido en 1949, en esta ocasión los misioneros sí quedaron plenamente satisfechos de su paso por La Unión. ${ }^{47}$

En los actos misionales para obreros no se abordaban temas de tipo social o laboral. Antes del inicio de cada misión, los misioneros recibían unas instrucciones escritas de parte de la Asesoría Eclesiástica de Sindicatos y entre ellas se encontraba, indefectiblemente, la siguiente advertencia:

"Tengan en cuenta los Padres Misioneros que los temas que han de tratar son los tradicionales. Aún en las conferencias que dirijan a los obreros en los centros de trabajo han de versar sobre temas religiosos. Eviten el tema social: tan sólo para explicarlo cuando sea necesario para aclarar los deberes propios contenidos en los Mandamientos de la Ley de Dios o de la Iglesia". ${ }^{48}$

Así las cosas, las conferencias y charlas impartidas en centros de trabajo debían presentar un contenido estrictamente religioso. De este modo, la Asesoría Eclesiástica de Sindicatos optaba por continuar la tradición más conservadora del catolicismo social español, aquella que excluía deliberadamente cualquier cuestionamiento de las relaciones sociolaborales establecidas y basaba sus estrategias de comunicación en promover una aceptación resignada de la propia condición social. Ni el Concilio Vaticano II, ni el desarrollo en otros ámbitos eclesiásticos de movimientos de obreros católicos de fuerte impronta crítica -como la HOAC-, llevaron a la Asesoría replantearse su metodología tradicionalista. ${ }^{49}$

46. Boletín de Información..., $\mathrm{n}^{\circ} 1,1950$.

47. AGA, AES, Misiones en la zona minera de La Unión, 1961, Caja 23-3.

48. AGA, AES, Instrucciones a los misioneros, s.f., Caja 10.

49. La bibliografía sobre los movimientos de apostolado obrero renovadores, como la HOAC, es muy abundante, pero son muy escasas las referencias a la pervivencia de modelos 


\section{Buscando unanimidades: el "acto general"}

Como hemos ido viendo, a lo largo de cada uno de los días de la misión se iban sucediendo actos dirigidos a grupos sociales específicos: niños, mujeres, jóvenes, obreros... Sin embargo, al final de cada día, en la tarde-noche, se llevaba a cabo un "acto general" al que estaban convocados todos los habitantes de la localidad misionada y que se celebraba dentro de la iglesia o, si ésta carecía de la capacidad necesaria, en locales habilitados al efecto -cines o teatros-, o incluso en medio de la calle, si la meteorología de la estación lo permitía.

En este acto general se esperaba contar con la máxima asistencia posible. En realidad, se esperaba contar con la asistencia de toda la población y cualquier ausencia, por minoritaria que fuese, era considerada una anomalía. En localidades pequeñas los misioneros podían llegar a identificar, con nombres y apellidos, a los que no asistían y visitarlos en sus domicilios particulares, con la finalidad de convencerlos para que compartiesen el "fervor" de sus vecinos. Aquellas personas cuya separación de la Iglesia era más notoria, como los adultos no bautizados o las parejas que convivían sin estar casadas, eran sometidas a una presión abrumadora, siendo visitadas por los misioneros y, de este modo, señaladas públicamente ante el resto de la comunidad. A menudo, estas presiones obtenían el fruto apetecido. En las misiones llevadas a cabo durante los años de la inmediata posguerra los bautismos de adultos fueron una escena habitual. Todavía durante la década de 1950 se dieron con cierta recurrencia. Así, durante la campaña misional celebrada en la isla de Tenerife en 1950 la localización de adultos no bautizados constituyó una de las preocupaciones prioritarias y fueron numerosos los que, de este modo, recibieron tal sacramento. ${ }^{50}$ Por lo que respecta a los matrimonios de "amancebados", también fueron un componente destacado de las misiones de la Asesoría. A modo de ejemplo, en Las Anorias, localidad perteneciente al municipio de Pétrola (Albacete), la misión celebrada en 1951 se saldó con cuatro matrimonios de parejas "amancebadas", con la peculiaridad de que dos de ellas recibieron por primera vez, en un mismo día, los sacramentos de la confesión, la comunión y el matrimonio. ${ }^{51}$

de apostolado tradicionales. Algunas referencias interesantes en: RodríguEz LaGo, José R., La Iglesia en la Galicia del franquismo (1936-1965). Clero secular, Acción Católica y Nacional-catolicismo, Sada, Edicions do Castro, 2004, pp. 395 y ss.

50. AGA, AES, Misión en Santa Cruz de Tenerife, 1950, Caja 25. Preocupación primordial de los misioneros era el administrar la primera comunión a adultos que no la habían recibido nunca. Así, durante una misión celebrada en la zona de Cartagena, en 1961, se administró la primera comunión a un grupo de adultos dentro del cual había personas de hasta 50 y 60 años: Boletín de Información..., nº 49, 1962.

51. Boletín de Información..., $\mathrm{n}^{\circ}$ 8, 1951. 
En el intento de que toda la población, sin excepciones, se congregase en el acto general se ponía de manifiesto la voluntad totalizadora de las misiones. Durante la duración de éstas la vida de la localidad misionada quedaba en suspenso, viéndose relegadas las actividades cotidianas ante el programa de actividades religiosas. El espacio público quedaba sacralizado a través de la presencia de elementos simbólicos que se colocaban en el mismo, tales como crucifijos, altares callejeros, carteles o pancartas. La llamada constante a la asistencia de todo el pueblo, sin excluir, como hemos visto, el recurso a la coerción, obedecía a una concepción totalizante de la religiosidad. En numerosas localidades se colocaban altavoces en puntos estratégicos de su callejero a través de los cuales eran retransmitidas, a alto volumen, las alocuciones de los misioneros con la finalidad, explícitamente reconocida, de que los que se negaban en redondo a asistir a los actos misionales "no tuviesen más remedio que escucharlos". ${ }^{52}$ La misión buscaba, ante todo, restaurar la comunidad cristiana tradicional, entendida ésta como una identificación total entre Iglesia y pueblo, sin que pudiera existir espacio para el disenso o la indiferencia.

Para el acto general de la tarde-noche los misioneros reservaban sus recursos más espectaculares, aquellos que presentaban un contenido más teatral y que, por ello mismo, enlazaban más directamente con el modelo barroco de misión. Las charlas que pronunciaban en tal acto apelaban a la emotividad del auditorio, intentando generar una situación de "pathos" colectivo que predispusiese a los asistentes a regresar a la fe. Uno de los temas más tratados era el de la muerte, pudiendo éste ser abordado de diferentes formas: la muerte reciente de algún ser querido que llevaría a replantearse el sentido de la existencia o la perspectiva de la propia muerte, que llevaría a plantearse la necesidad de "reconciliarse con Dios". Un recurso muy utilizado por los misioneros era el de interrumpir su charla para rezar tres avemarías: el primero por el éxito de la misión, el segundo por aquel de los presentes cuya alma estuviese más "descarriada" y el tercero por el que primero fuese a morir. Un misionero capuchino tenía la costumbre de hacer que las luces de la iglesia fuesen apagadas, sorpresivamente, en el momento en que comenzaba la primera de las tres oraciones, mientras en el campanario de la iglesia comenzaba un lento redoble de campanas. Cuando, finalizadas las oraciones, las luces volvían a encenderse eran visibles las señales de emoción en muchos de los asistentes. En algunas misiones había una noche en la que el acto general se celebraba en el cementerio, hacia el cual los fieles se dirigían en comitiva. Allí, el misionero les dirigía el denominado "sermón de la muerte". El ambiente nocturno y el verbo emotivo de

52. Boletín de Información..., $\mathrm{n}^{\circ}$ 26, 1956. 
los misioneros hacían que fuesen muchos los que se emocionasen, no siendo inhabitual que algunos de los asistentes pidiesen ser oídos en confesión nada más terminar. ${ }^{53}$

\section{El final de la misión: "misa de campaña" y despedida}

La misión había ido desarrollándose con sus actos específicos y generales. La vida de la localidad se había visto sacralizada por la acción de los misioneros, produciéndose una nueva dinámica social que alteraba las rutinas establecidas. Pero, inevitablemente, llegaba un día en que todo debía terminar.

El acto final de la misión solía coincidir con un domingo y consistía en una "misa de campaña", celebrada en un espacio público abierto, habitualmente la plaza central del pueblo. A esta misa se esperaba que asistiese toda la localidad. Aún más: se esperaba que en el transcurso de la misma comulgasen todos los miembros de la localidad que, por su edad, estuviesen en disposición de hacerlo o, por lo menos, el mayor número posible de ellos. El objetivo último de las misiones era que todos los habitantes de la localidad misionada -o, por lo menos, la inmensa mayoría de ellos- entrasen en "gracia de Dios" por la vía de recibir los sacramentos de la confesión y la comunión. Del mayor o menor número de comuniones distribuidas durante el acto final dependía, por lo tanto, el que la misión pudiese ser considerada un éxito o un fracaso. El acto final constituía, de este modo, el momento en que quedaba de relieve si los esfuerzos desarrollados por los misioneros durante los días de misión habían dado verdadero fruto y se podía considerar que la comunidad había entrado en la vía de la recristianización.

Desde horas muy tempranas, los misioneros empezaban a escuchar confesiones. Les auxiliaba el clero local y, en ocasiones, sacerdotes de refuerzo llegados desde localidades limítrofes. La sucesión de confesiones podía llegar a demorarse durante horas. Si la misión había logrado generar un clima de entusiasmo religioso entre la población, era normal que se acercasen a confesar personas que llevaban muchos años sin hacerlo. Eran las famosas "confesiones de diez, veinte y hasta treinta años", que entusiasmaban a los misioneros, pues veían en ellas la prueba más palpable de que "el pueblo estaba siendo reconquistado para el Señor". ${ }^{54}$

Si en la localidad existía alguna imagen religiosa que fuera objeto de devoción popular, podía llevarse a cabo una procesión con la misma antes de la misa. Dicha procesión culminaba en el mismo sitio donde la misa iba a celebrarse y

53. AGA, AES, Misiones en la provincia de León, 1959, Caja 23-3.

54. AGA, AES, Misiones en la provincia de Almería, 1967, Caja 23-1.

Pasado y Memoria. Revista de Historia Contemporánea, 14, 2015, pp. 227-253 
la imagen era colocada frente al altar, en una posición preferente. De este modo, al dotar al acto de una connotación extraordinaria y festiva, se conseguía asegurar una asistencia masiva. Este recurso resultaba particularmente eficaz en el mundo rural andaluz, donde estaba fuertemente extendido el fenómeno de que personas que no eran asistentes habituales a la iglesia, sí profesasen una fuerte devoción a una imagen religiosa concreta y estuviesen dispuestas a asistir a cualquier procesión que tuviese a dicha imagen como protagonista. La religiosidad popular era puesta, de este modo, al servicio de la religiosidad oficial que representaban las misiones..$^{55}$

Desde finales de la década de 1950, la Asesoría Eclesiástica de Sindicatos elaboró estadísticas acerca del número de personas que asistían a los actos generales de las misiones. De un análisis inicial de estos datos, se extrae la idea de que las misiones, a pesar del fuerte despliegue propagandístico que conllevaban, no lograban modificar la estructura religiosa tradicional de las localidades donde se llevaban a cabo. Así, en provincias de Castilla como Palencia, León o Ávila, donde los índices de asistencia a misa y frecuencia en la comunión habían sido tradicionalmente muy altos, las misiones solían saldarse con asistencias masivas, a menudo casi unánimes. Por el contrario, en provincias de Andalucía como Córdoba, Jaén o Almería, donde los índices de asistencia a misa y comunión dominical eran, de partida, muy bajos, los actos generales de las misiones se saldaban con asistencias mucho menos espectaculares. ${ }^{56}$

El Cuadro 1 nos muestra esta dinámica a través de la comparación de dos campañas misionales llevadas a cabo en zonas mineras: una en la provincia de Palencia, en 1958, y otra en el entorno de Peñarroya-Pueblonuevo (Córdoba), en 1964. La misión de Palencia se llevó a cabo en una sociedad donde los índices de participación en la comunión eran altísimos antes de la llegada de los misioneros. Los datos de asistencia a la misión no hicieron sino confirmar dicha situación preexistente. Los misioneros no llevaron a cabo un proceso de recatolización de las masas, sino que vinieron a reforzar una situación de consenso casi unánime en torno a la religión católica que ya existía previamente. Por su parte, la misión de Peñarroya-Pueblonuevo se desarrolló en una sociedad donde participaba en la comunión menos del 50 por 100 de la población

55. LARA LóPEZ, Emilio L., "Nacionalcatolicismo y religiosidad popular (1936-1953). Un análisis de documentación fotográfica", Historia, antropología y fuentes orales, no 29 (2003), pp. 71-83.

56. La dicotomía entre un norte de España con altos índices de práctica religiosa y un sur con índices sensiblemente más bajos venía siendo señalada por la sociología católica desde comienzos del siglo XX. Un resumen general de esta cuestión en: LanNon, Frances, Privilegio, persecución y profecía. La Iglesia católica en España, 1875-1975, Madrid, Alianza, 1990, pp. 25 y ss. 
habilitada para ello y en la que, por tanto, el consenso en torno al catolicismo estaba lejos de la unanimidad. Nuevamente, la asistencia a la misión no vino sino a refrendar la tendencia preexistente: se movilizaron para acudir a los actos misionales quienes ya mantenían un compromiso activo con los ritos católicos, fracasando los misioneros en su intento de involucrar a quienes vivían apartados de los mismos.

\section{Cuadro 1.- Misiones en las cuencas mineras de Palencia (1958) y Peñarroya-Pueblonuevo (1964)}

\begin{tabular}{|l|r|r|}
\hline & Palencia & Peñarroya-Pueblonuevo \\
\hline Población localidades misionadas & 29.509 & 35.148 \\
\hline Cumplimiento dominical (\%) & 81,32 & 37,50 \\
\hline Cumplimiento pascual (\%) & 91,41 & 44,50 \\
\hline Asistencia a la misión (\%) & 89,66 & 40,51 \\
\hline
\end{tabular}

Fuente: Elaboración propia a partir de fuentes AGA, AES. ${ }^{57}$

Podríamos, por lo tanto, lanzar la hipótesis de que las misiones no dieron lugar a una auténtica reconquista católica sino que, más bien, contribuyeron a mantener el "statu quo" religioso tradicional de las regiones españoles. En regiones como Castilla, donde los índices de práctica religiosa eran ya muy altos desde antes de la Guerra Civil, contribuyeron a mantener en el tiempo tal situación. Y en regiones como Andalucía, donde tales índices eran, de partida, bajos, sirvieron para que no terminasen de hundirse y, quizás, para mejorarlos levemente, pero no para generar un vuelco espectacular de la tendencia histórica.

La misa de campaña ponía fin a los actos misionales propiamente dichos, pero aún había espacio para un epílogo: la "despedida de los misioneros", que podía tener lugar el mismo domingo en que finalizaba la misión, por la tarde, o bien a la mañana siguiente. Este acto de despedida tenía lugar en un espacio abierto, generalmente la plaza principal. El alcalde dirigía unas palabras a los misioneros y éstos le daban, literalmente, "un abrazo a todo el pueblo en la per-

57. "Cumplimiento dominical": porcentaje de personas que comulgaban cada domingo antes de la llegada de los misioneros, según estimación de los párrocos. "Cumplimiento pascual": porcentaje de personas que comulgaban por Pascua antes de la llegada de los misioneros, según estimación de los párrocos. "Asistencia a la misión": porcentaje de asistencia a los actos generales de la misión, según estimación de los misioneros. La misión de Palencia afectó a los municipios de Guardo, Mantinos, Velilla del Río Carrión, Santibáñez de la Peña, Castrejón de la Peña, La Pernía, Cervera de Pisuerga, Mudá, San Cebrián de Mudá, Barruelo de Santullán y Brañosera. La de Córdoba a: PeñarroyaPueblonuevo, La Granjuela, Valsequillo, Los Blázquez, Belmez y Villanueva del Rey. 
sona del alcalde". Seguidamente, los misioneros dirigían unas palabras finales a la multitud congregada, exhortando a todos a perseverar en el nuevo camino religioso iniciado a raíz de la experiencia misional. La multitud, por su parte, correspondía con gritos a través de los cuales pedía a los misioneros "que no se marchasen". Si la localidad contaba con banda de música, ésta interpretaba su repertorio. Los misioneros partían. El vehículo en que viajaban era perseguido durante varios kilómetros por los niños. Como recuerdo de los días vividos quedaba la "cruz misional", una cruz de madera colocada en un lugar destacado de la localidad que pretendía que la comunidad no olvidase el compromiso de llevar una vida más cristiana que había adquirido ante los misioneros.

\section{Conclusión}

Las campañas misionales proliferaron en España después de la Guerra Civil como un instrumento utilizado por la Iglesia para reconstruir la sociedad católica tradicional, entendida ésta como una comunidad de creyentes sin fisuras en la que no había lugar para la cultura secularizada que desde las distintas vertientes del liberalismo y el socialismo se venía afirmando desde el siglo XIX.

Desde 1949, la Asesoría Eclesiástica de Sindicatos jugó un importante papel en el proceso de organización de misiones. La Asesoría llevaba a cabo sus misiones en comarcas donde no existían grandes ciudades pero donde se concentraban importantes contingentes de población obrera. Sin embargo, sus misiones no eran, estrictamente hablando, "misiones para obreros", dado que buscaban involucrar a toda la población de las localidades misionadas, independientemente de su clase social.

Las misiones de la Asesoría respondían a un modelo de evangelización de clara raigambre barroca. Cuando comparamos las crónicas misionales redactadas en el siglo XVII con las que los misioneros de la Asesoría remitían a la Sección de Apostolado de la misma cada vez que finalizaba una campaña encontramos sorprendentes similitudes y persistencias. El programa de actos en torno al cual giraban las misiones era, con escasas variaciones, el mismo: la misión infantil, el rosario de la aurora o el vía crucis estaban ya firmemente asentados en la misión barroca y se desarrollaban con planteamientos muy similares a los que tres siglos más tarde pondría en liza la Asesoría Eclesiástica de Sindicatos. En la misión barroca existía una preferencia por los recursos efectistas, basados en las ideas de muerte, pecado y salvación, que persistía en las misiones de la Asesoría. Tanto en uno como en otro caso la acción misional estaba inspirada por una voluntad fuertemente totalizadora: se buscaba que la vida de una localidad entera, sin excepciones, girase en torno a los actos misionales mientras éstos durasen y para lograr este fin no se renunciaba a la coerción. 
Lograr el máximo número de comuniones posible era la finalidad última de la misión, pues se consideraba que ello constituía la muestra más evidente de la recristianización de la sociedad. Sin embargo, los datos estadísticos sobre asistencia a los actos generales en las distintas misiones, recogidos por la propia Asesoría, ponen de relieve que aquéllas no alteraban sustancialmente la sociología religiosa tradicional de las distintas regiones españolas. 